\title{
Agro-morphological traits-based genetic diversity assessment in Ethiopian barley (Hordeum vulgare L.) landrace collections from Bale highlands, Southeast Ethiopia
}

\author{
Fekadu Gadissa $^{1 *} \mathbb{D}$, Meskerem $_{\text {Abebe }}^{2}$ and Tesfaye Bekele ${ }^{1}$
}

\begin{abstract}
Background: Cultivated barley (Hordeum vulgare L.) is one of the world's important cereal crops. Ethiopia is claimed to be the centre of origin due to its high phenotypic diversity and flavonoid patterns. It is widely cultivated on subsistence bases and important in supporting the livelihood of local poor. However, the local landraces are currently under threat of severing genetic erosion. Hence, assessing the extents of its genetic diversity is timely in improvement and conservation.
\end{abstract}

Methodology: 120 representative cultivated barley landraces have been collected from Bale highlands, Ethiopia, and tested at two locations using alpha lattice design. Data were collected on 21 agro-morphometric traits and analysed using MINITAB 19, SAS 9.4 and FigTree v1.4.3.

Results: Most morphotypes in each of the qualitative traits considered and mean performance values in most of the quantitative traits revealed wide range of variations suggesting existence of phenotypic diversity among the landraces. Analysis of variance also showed significant variations among the landraces. All the traits, except days to maturity and plant height showed a significant variation for location and treatment-location interactions revealing the high impact of environmental conditions on the variations. Estimates of the variance components also revealed a wider range of variations in most of the traits considered with eventual medium to low genotypic (GCV), phenotypic (PCV) and genotype-environment coefficients of variation (GECV). Estimates of heritability in broad sense $\left(\mathrm{H}^{2}\right)$ is low $(<40 \%)$ in all the traits except in days to maturity. Grouping of the landraces showed poor geographic areas of collection-based pattern suggesting extensive gene flow among the areas.

Conclusion: The landraces evaluated in the present study showed high morphological diversity. However, the effect of environment factor is pronounced and thus, multiple locations and years with large number of samples must be considered to exploit the available genetic-based variations for breeding and conservation of the crop.

Keywords: Barley, Genetic diversity, Hordeum vulgare, Landraces, Morphological traits

*Correspondence: fikega2000@gmail.com

1 Department of Biology, Madda Walabu University, P.O. Box 247, Bale Robe, Ethiopia

Full list of author information is available at the end of the article permits use, sharing, adaptation, distribution and reproduction in any medium or format, as long as you give appropriate credit to the original author(s) and the source, provide a link to the Creative Commons licence, and indicate if changes were made. The images or other third party material in this article are included in the article's Creative Commons licence, unless indicated otherwise in a credit line to the material. If material is not included in the article's Creative Commons licence and your intended use is not permitted by statutory regulation or exceeds the permitted use, you will need to obtain permission directly from the copyright holder. To view a copy of this licence, visit http://creativecommons.org/licenses/by/4.0/. The Creative Commons Public Domain Dedication waiver (http://creativeco mmons.org/publicdomain/zero/1.0/) applies to the data made available in this article, unless otherwise stated in a credit line to the data. 


\section{Background}

Barley (Hordeum vulgare L.) is an annual grass belonging to the family Poaceae (Gramineae). It is thought to have been originated from its wild progenitor, Hordeum spontaneum (C. Koch) Thell, in the 'Fertile Crescent' area of the Near East at around $7000 \mathrm{BC}$ [1]. It is among the first domesticated cereal crops and has long history of cultivation that extends to more than 10,000 years ago. It is the fourth most important cereal crop, next to wheat, maize and rice and is among the top ten crop plants across the world [2].

Ethiopia is recognized as the secondary centre of diversity due to lack of wild relatives [3]. However, others signify the country as the centre of origin because of the large phenotypic diversity [4] and high flavonoid patterns [5] in Ethiopian landraces. In terms of coverage and cultivation, it is the country's major traditional cereals, together with teff (Eragrostis tef (Zucc.) Trotter), maize (Zea mays L.), wheat (Triticum ssp.), and sorghum (Sorghum bicolor L. Moench), and represents nearly $13 \%$ of the total national cereal production [6]. In Bale administrative zone, one of the potential agricultural areas in the country, it is the largest agricultural commodity and covers the largest production area next to wheat.

Over $90 \%$ of the barley cultivated in Ethiopia and Bale administrative zone is represented by landraces that are largely produced through subsistence farming with little or no application of fertilizers, pesticides and herbicides $[7,8]$. In addition, they usually have a good adaptive potential to local conditions and are able to tolerate environmental stresses including drought, water logging, frost, soil acidity and degradation. In addition, they are tolerant to diseases and pests [8]. Such wide adaptations are partly attributed to the diverse agro-ecological conditions, large number of folk varieties and tremendous traditional management practices of the country $[9,10]$.

The landraces are mainly produced to support food security of the subsistence farmers unlike in developed countries. Thus, in the current scenario of climate change, they are eminent and potential sources of breeding materials $[11,12]$. However, according to the reports by Worede et al. [13] and others, the native barley landraces suffer from serious genetic erosion to the extents of total loss. Several landraces which had been under wide cultivation during the past decades in the country in general and in Bale administrative zone in particular have been lost in recent times. Such noticeable genetic erosion is largely attributed to lack of research interventions targeting its improvement, a shift towards commercial barley verities and the widespread climate change related degradation. Therefore, the present study was initiated to assess the extents of genetic diversity in Ethiopian barley landraces and to properly manage the genetic resources and to generate pre-hand information to assist the improvement programmes and proper designing of ex situ and in situ conservation measures.

\section{Materials and methods Plant material}

In total, 120 representative barley (Hordeum vulgare L.) landrace samples were collected from 120 potential administrative kebles (the smallest administrative structure) that constituted a total of 10 administrative woredas in Bale Zone, Ethiopia (Fig. 1, Table 1, Additional file 1). The seed samples were collected from the stored seeds of selected volunteer farmers who are well experienced in barley landrace farming. The identity of the samples was confirmed using the species description provided in Flora of Ethiopia and Eritrea [14].

\section{Test environment}

Field experiment was carried out at Agarfa Agricultural Technical and Vocational Education and Training (TVET), which is part of the Ethiopian Agricultural TVET colleges and Madda Walabu University main campus research stations, Bale, Southeast Ethiopia. The stations were selected because of their suitability and familiarity for barley production. The experiment was conducted for one year during the main cropping season, usually called 'ganna' (June to October) of 2018/2019.

Agarfa agriculture TVET field station is located at $458 \mathrm{~km}$ from Addis Ababa, the capital of Ethiopia in the Southeast direction $\left(40^{\circ} 43^{\prime} \mathrm{E}\right.$, and $\left.6^{\circ} 67^{\prime} \mathrm{N}\right)$. The area is $2350 \mathrm{~m}$ above sea level (m.a.s.l) and receives an average annual rainfall of $836.70 \mathrm{~mm}$ with mean minimum and maximum temperature of $8.6^{\circ} \mathrm{C}$ and $22.4^{\circ} \mathrm{C}$, respectively [15]. It has predominantly vertisol and clay soil types. Madda Walabu University main campus research field is located at $430 \mathrm{~km}$ from Addis Ababa in the southeast direction $\left(39^{\circ} 59^{\prime} \mathrm{E}, 7^{\circ} 08^{\prime} \mathrm{N}\right)$. The station is $2088 \mathrm{~m}$ above sea level and receives an annual rainfall of $860 \mathrm{~mm}$ and a mean maximum and minimum annual temperatures of $25.2{ }^{\circ} \mathrm{C}$ and $9.4{ }^{\circ} \mathrm{C}$, respectively [15]. It has a cambisol with minor occurrence of vertisol soil type.

\section{Experimental design}

The experiment was conducted using an incomplete random block design called alpha lattice design with three replications per site and four blocks (each having 30 plots that comprise a total of $4.5 \mathrm{~m}^{2}$ ) in each replication and each site. Each sample was represented by ten distinct seeds and grown in a single row on a separate plot in each replication. Position of the samples within a block was randomly assigned with a spacing of $0.15 \mathrm{~m}$ between successive plots and $0.10 \mathrm{~m}$ between plants (seeds) in a plot. The spacing between blocks and replications was 


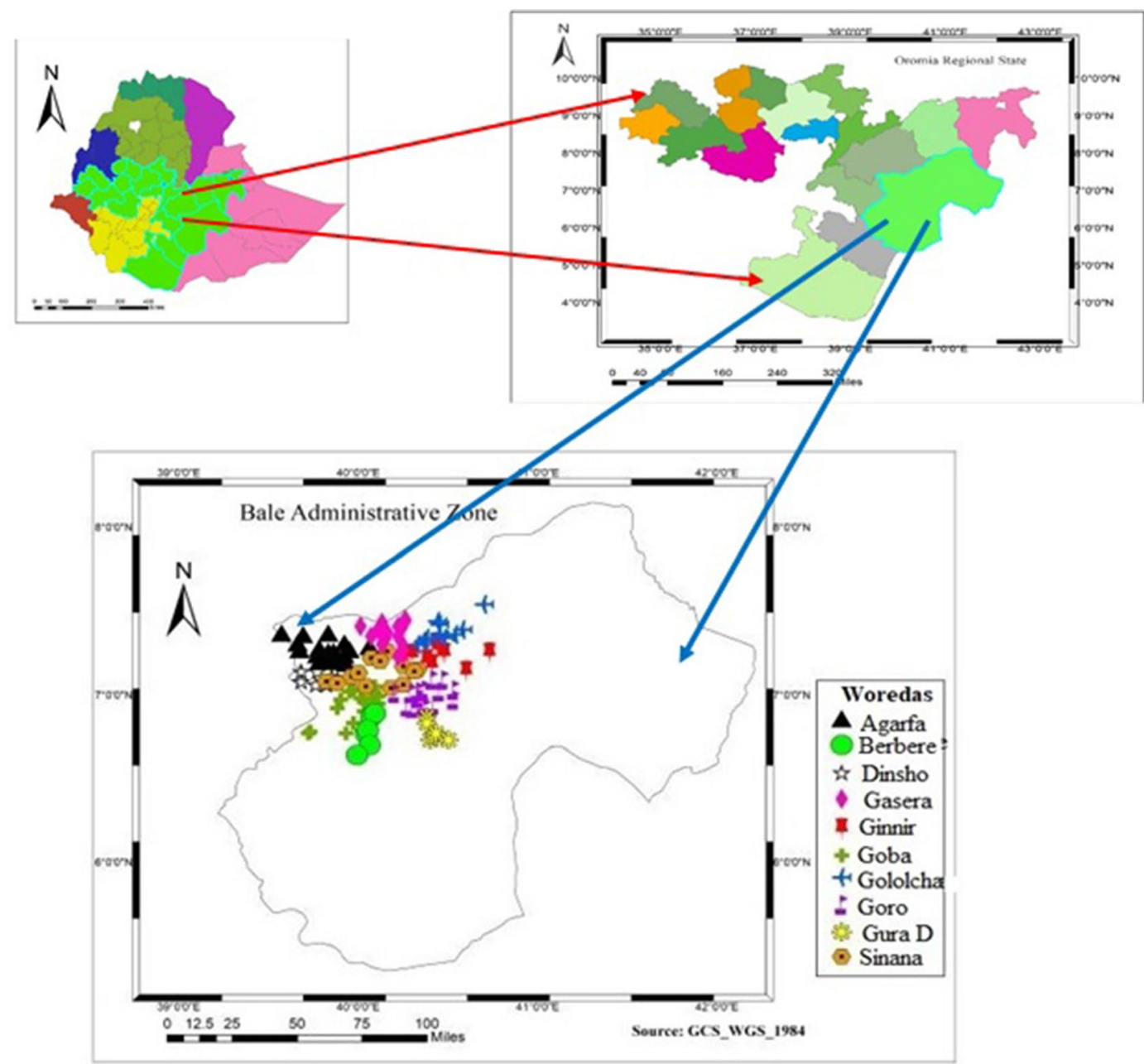

Fig. 1 A map of Ethiopia with its federal administrative regions (left up) showing barley landraces collection administrative region, Oromia (right up) and administrative zone, Bale (bottom). The map was constructed based on geographic coordinates and elevation data gathered from each collection sites using global positioning system (GPS); Gura D under "woredas" represents Gura Damole

$1 \mathrm{~m}$ each. At both sites, planting was done at the beginning of the rainy season (mid-June) on a well-prepared soil. All the recommended agronomic practices for the crop such as tinning, hand weeding, fertilizers $(100 \mathrm{~kg} / \mathrm{ha}$ DAP and $50 \mathrm{~kg} / \mathrm{ha}$ urea were applied at planting and knee height, respectively), and pesticides were applied during the growing period.

\section{Data collection}

During the study, barley (H. vulgare) specific standard descriptor lists developed by IPGRI [16], and the descriptors frequently used by Tanno et al. [17] and Negassa [18] were used. In total, 21 agro-morphometric (7 qualitative and 14 quantitative) traits were recorded at the correct growth stages (Additional file 2). For most of the quantitative traits, data were collected from seven selected and tagged middle plants for each sample, per replication, per site. However, some like days to sowing and days to $50 \%$ heading were recorded on plot basis. For qualitative morphological traits, recording was done on plot bases. Seed yield per hectare (SYPH) was calculated based on the average fresh weight of grain from the seven sampled plants per plot.

\section{Statistical analysis}

Distribution frequency of all the qualitative traits considered was analysed and tabulated using MINITAB 19 [19]. All univariate analyses of the quantitative traits were done using Statistical Analysis Computer Software (SAS 9.4). Accordingly, after Hartley's F-max based error variance homogeneity test [20], pooled analysis of variance (ANOVA) was conducted to quantify the total variation 
Table 1 Summary of sampling woredas in Bale zone, Ethiopia, with their respective number of samples that represent the total 120 landrace samples as well as their range of range of altitude, latitude, and longitude

\begin{tabular}{lcllll}
\hline $\begin{array}{l}\text { Sampling } \\
\text { woreda } \\
\text { (population) }\end{array}$ & $\begin{array}{l}\text { Number } \\
\text { of } \\
\text { Samples }\end{array}$ & $\begin{array}{l}\text { Altitude } \\
\text { (m.a.s.I) }\end{array}$ & \multicolumn{2}{l}{ GPS-reading (DD) } \\
\cline { 4 - 6 } & 17 & $1992-3114$ & $7.19-7.37$ & $39.57-40.06$ \\
\hline Agarfa & 6 & $1591-2103$ & $6.64-6.89$ & $39.99-40.09$ \\
Berebere & 8 & $2801-3354$ & $7.06-7.14$ & $39.68-39.88$ \\
Dinsho & 17 & $1745-2412$ & $7.23-7.45$ & $40.01-40.26$ \\
Gasera & 9 & $1888-2375$ & $7.14-7.31$ & $40.3-40.73$ \\
Ginnir & 18 & $2434-3500$ & $6.77-7.05$ & $39.72-40.11$ \\
Goba & 10 & $1907-2526$ & $7.30-5.54$ & $40.33-40.70$ \\
Gololcha & 16 & $1750-2623$ & $6.92-7.09$ & $40.20-40.53$ \\
Goro & 6 & $1741-2226$ & $6.73-6.87$ & $40.38-40.50$ \\
Gura Damole & 13 & $2341-3000$ & $7.04-7.26$ & $39.82-40.33$ \\
Sinana & 120 & & & & \\
Total sample & $\mathbf{1 2 0}$ & & &
\end{tabular}

Number in bold indicates total sample size or total score for each character

among the samples using the following linear additive model: $P_{i j k s}=\mu+\tau_{i}+\beta_{k(j)(s)}+\pi_{j(s)}+L_{s}+(\tau x l)_{i s}+E_{i j}$ ks where, $P_{\mathrm{ijks}}=$ phenotypic value of ith treatment (samples) under jth replication at sth location and kth incomplete block within replication $j$ and location $s ; \mu=$ grand mean; $\tau_{i=}$ the effect of ith treatment; $\beta_{\mathrm{k}(\mathrm{j})(\mathrm{s})}=$ the effect of incomplete block $k$ within replication $j$ and location s; $\pi_{\mathrm{j}(\mathrm{s})=}$ the effect of replication $j$ within location $s ; \mathrm{L}_{\mathrm{s}}=$ the effect of location; $(\mathrm{txl})_{\text {is }}=$ the interaction effects between treatment and location, and $E_{\mathrm{ijks}}=$ pooled error. Significance tests among the samples, locations and samplelocation interaction effects were determined using the F-test. Mean separation was done using least significance difference tests (LSD) at 5\% probability levels.

Estimation of environmental, genotypic and phenotypic variance components and their coefficients of variation per location and pooled over locations were done following the description of Singh and Chaudhary [21].

Broad-sense heritability $\left(\mathrm{H}^{2} \%\right)$ per location and combined over locations, expected genetic advance (GA) under selection, assuming the selection intensity at 5\%, were estimated according to Allard [22]. Similarly, genetic advance as percent of the mean was calculated as: GA $(\%$ of mean $)=(\mathrm{GA} / \mathrm{m}) \times 100 \%$ where, $\mathrm{GA}=$ genetic advance; $\mathrm{m}=$ sample mean for the trait considered.

Pairwise phenotypic and genotypic correlation coefficients were determined by using the variance and covariance components as described in Singh and Chaudhary [21] and Sharma [23]. Significances of the correlation coefficients were tested following the formula suggested by Robertson [24].
All multivariate analyses such as principal components (PC) were conducted for combined and standardized sample means using MINITAB 19 [19]. Cluster analysis and pairwise generalized square distance $\left(D^{2}\right)$ between clusters were computed using SAS 9.4 and different branches of the trees were differently colored using FigTree v1.4.3 [25].

\section{Results \\ Analysis of the distribution frequency in qualitative (phenetic) traits}

The qualitative agronomic morphological traits considered were grouped into seed, stem, lemma or awn characteristics and each group were represented by several morphotypes (Table 2) most of which are proportionally distributed, but some are rare. The details are presented below.

\section{Stem characteristics}

Two stem-related characteristics: stem pigmentation and stem growth habit have been evaluated. Accordingly, most of the collections exhibited green stem pigmentation (80.2\%) and erected (upright and longer) stems (73.8\%). Collections with purple $(16.3 \%)$ stem pigmentation either at basal only (16.3) and/or at half or more of the stem (3.5), intermediate (14.3\%) and prostate (12.2\%) growth habits were less frequent (Table 2).

\section{Seed characteristics}

Three seed-related characteristics: kernel row number, grain, and glumes colours have been considered and all showed variations among the collections. Accordingly, white glume $(41.1 \%)$ and grain $(51.1 \%)$ colours are more frequent among the collections than yellow (28.6\%), and brown glumes colours (16.3\%). Similarly, considerable number of the collections had brown glume (18.6\%) and grain $(23.6 \%)$ colures. Purple, red, and black glume and grain colures appeared less frequent. With regard to kernel row number, larger number of the collections (59.2\%) had six-rowed kernels out of which nearly $16.2 \%$ were six-rowed with long awns. The remaining collections exhibited two-rowed (25.3\%) and irregular kernel types (15.0\%). Collections with two-rowed deficient, and variable lateral florets were almost null (Table 2).

\section{Lemma characteristics}

Lemma related characteristics again showed variations among the tested collections. Accordingly, collections with no lemma teeth are dominant $(57.1 \%)$ followed by those with lemma hair (30.3\%) and lemma teeth (12.2\%) types (Table 2). 
Table 2 Group characters, individual standard traits along with their phenetic characters with their scores and frequency coverage (\%) in the 120 barley landrace collections from Bale highlands, Southeastern Ethiopia

\begin{tabular}{|c|c|c|c|c|}
\hline Group characters & Individual traits & Phenetic characters & Score & Frequency (\%) \\
\hline \multirow[t]{6}{*}{ Stem characteristics } & \multirow[t]{3}{*}{ Stem pigmentation } & Green & 1 & 80.2 \\
\hline & & Purple (basal only) & 2 & 16.3 \\
\hline & & Purple (half or more) & 3 & 3.5 \\
\hline & \multirow[t]{3}{*}{ Growth habit } & Prostate & 1 & 12.2 \\
\hline & & Intermediate & 2 & 14.3 \\
\hline & & Erect & 3 & 73.5 \\
\hline \multirow[t]{16}{*}{ Seed characteristics } & \multirow[t]{6}{*}{ Kernel row number } & Two rows & 1 & 25.3 \\
\hline & & Two-rowed deficient & 2 & 0.5 \\
\hline & & Irregular & 3 & 15.0 \\
\hline & & Variable lateral florets & 4 & 0.0 \\
\hline & & Six rows & 5 & 43.0 \\
\hline & & Six-rowed, long awns & 6 & 16.2 \\
\hline & \multirow[t]{4}{*}{ Grain color } & White & 1 & 51.1 \\
\hline & & Brown & 2 & 23.6 \\
\hline & & Red & 3 & 13.3 \\
\hline & & Black & 4 & 12.0 \\
\hline & \multirow[t]{6}{*}{ Glumes colour } & White & 1 & 40.1 \\
\hline & & Yellow & 2 & 14.3 \\
\hline & & Brown & 3 & 18.6 \\
\hline & & Red & 4 & 8.0 \\
\hline & & Purple & 5 & 6.0 \\
\hline & & Black & 6 & 13.0 \\
\hline \multirow[t]{3}{*}{ Lemma characteristics } & \multirow[t]{3}{*}{ Lemma type } & No lemma teeth & 1 & 57.1 \\
\hline & & Lemma teeth & 2 & 12.2 \\
\hline & & Lemma hair & 3 & 30.3 \\
\hline \multirow[t]{5}{*}{ Awn characteristics } & \multirow[t]{5}{*}{ Awn colour } & White & 1 & 40.8 \\
\hline & & Yellow & 2 & 14.3 \\
\hline & & Brown & 3 & 20.4 \\
\hline & & Reddish & 4 & 18.4 \\
\hline & & Black & 5 & 6.1 \\
\hline
\end{tabular}

Numbers in bold indicate total sample size or total score for each character

\section{Awn characteristics}

Awn-related characteristics also showed a wide range of variation among the tested collections. Accordingly, large number of the collections (40.8\%) revealed white awn colour followed by brown (20.4\%), red (18.4\%) and yellow $14.3 \%)$, respectively. Collections with black awn colour were very rare (only $6.1 \%$ of the total) (Table 2 ).

\section{Patterns of variation in the quantitative traits considered Patterns of the traits mean performance}

Summary of the range between maximum and minimum mean performance values, range unit and the pooled means for the 14 quantitative traits computed using data combined over the test locations is presented in Table 3. In general, the barley landraces considered in the present study showed a considerable wide range of variability or wide range between the maximum and minimum mean performance values in most of the quantitative traits considered. Accordingly, single leaf area $(\boldsymbol{S} \boldsymbol{L} \boldsymbol{A})$ revealed the widest range $\left(1074.86-1580.16 \mathrm{~cm}^{2}\right)$ that extends to range units of $505.3 \mathrm{~cm}^{2}$ with the traits pooled mean performance of $1263.42 \pm 178.19 \mathrm{~cm}^{2}$. Days to maturity (DTM) (111.99-140.83 days; or range unit of 28.84 days), number of grains per plant (NGPP) (23.52-41.60 grains; or range units of 18.08 grains), and thousand seed weight (TSW) (33.21-45.25 g; or range unit of $12.04 \mathrm{~g}$ ) having traits pooled mean performance of $119.34 \pm 6.13$, $32.69 \pm 4.63$, and $38.99 \pm 3.99$ in that order, ranked second, third and fourth, respectively. Four traits: days to heading $(\boldsymbol{D} T \boldsymbol{H})$, awn length $(\boldsymbol{A L})$, spike length $(\boldsymbol{S} \boldsymbol{L})$, and leaf width $(\boldsymbol{L W})$ revealed a moderate range of mean 
Table 3 Estimates of the range, range unit and mean along with standard errors computed using pooled data of the two test locations for the 14 quantitative traits used

\begin{tabular}{lccc}
\hline Traits & Range (min to max) & Range unit & Trait mean \pm SE \\
\hline DTH & $57.65-62.80$ & 5.15 & $59.99 \pm 1.61$ \\
DTM & $111.99-140.83$ & 28.84 & $119.34 \pm 6.13$ \\
AL & $12.96-16.03$ & 3.07 & $14.59 \pm 0.87$ \\
SL & $8.23-10.55$ & 2.32 & $9.74 \pm 0.46$ \\
FLL & $28.79-35.71$ & 6.92 & $32.96 \pm 2.16$ \\
LN & $5.20-6.42$ & 1.22 & $5.71 \pm 0.44$ \\
LW & $8.36-11.09$ & 2.73 & $9.16 \pm 0.46$ \\
SLA & $1074.86-1580.16$ & 505.30 & $1263.42 \pm 178.19$ \\
PH & $95.11-104.4$ & 9.29 & $99.42 \pm 2.94$ \\
EFT & $7.32-9.28$ & 1.96 & $8.38 \pm 0.55$ \\
NGPP & $23.52-41.60$ & 18.08 & $32.69 \pm 4.63$ \\
TSW & $33.21-45.25$ & 12.04 & $38.99 \pm 3.99$ \\
SYPP & $6.99-15.24$ & 8.25 & $10.60 \pm 2.23$ \\
SYPH & $1.40-3.05$ & 1.65 & $2.12 \pm 0.44$ \\
\hline DTHdays & headig DTMdays &
\end{tabular}

DTH days to heading, DTM days to maturity, AL awn length, SL spike length, $F L L$ flag leaf length, $L N$ leaf number, $L W$ leaf width, $S L A$ single leaf area, $P H$ plant height, EFT effective fertile tiller, NGPP number of grain per plant, TSW thousand seed weight, SYPP seed yield per plant, SYPH seed yield per hectare, SE standard error

performances (range units of 2.32-5.15). The remaining three traits: leaf number $(\boldsymbol{L N})$, seed yield per hectare $(\boldsymbol{S Y P H})$ and effective fertile tiller $(\boldsymbol{E F T})$ showed a relatively lower range of mean performances (less than 2 range units) (Table 3 ).

\section{Analysis of variance (ANOVA)}

Analysis of variance, determined using pooled data of the two test locations, is presented under Table 4. Accordingly, the mean square values in most of the traits (10 of the total 14 traits) showed variations among the landraces at different significance levels $(p<0.05 ; p<0.01$; $p<0.001)$. In addition, all those traits, except days to maturity and plant height showed a significant variation for location and treatment-location interactions revealing the high impact of environmental conditions. However, the mean square for replications within location and blocks within replication showed a non-significant variation in most of the traits suggesting the little environmental effect within the test locations.

More than half of the traits considered showed a moderately high $(\geq 0.50)$ coefficient of genetic determination $\left(\mathrm{R}^{2}\right)$ with effective fertile tiller $(\boldsymbol{E F T})(0.74)$ and spike length $(\boldsymbol{S L})(0.69)$ being the highest. Similarly, the coefficients of variation (CV) are less or equal to 26.38 (in seed yield per hectare $(\boldsymbol{S Y P H}))$ and seems moderate and within the acceptable range.

\section{Estimates of variance components, heritability in broad sense, and genetic advance}

Estimates of the variance components, heritability in broad sense, and genetic advance, computed using pooled data from the two test locations, is presented in Table 5. Accordingly, phenotypic variance $\left(\boldsymbol{\delta}_{\mathrm{p}}^{2}\right)$ estimate revealed a much wider variation that ranged from 0.09 in seed yield per hectare (SYPH) to 15,352.31 in leaf area

Table 4 Analysis of variance (ANOVA) for the 14 quantitative traits computed using data pooled over the two test environments

\begin{tabular}{|c|c|c|c|c|c|c|c|c|}
\hline Traits & Trt (119) & Loc (1) & $\operatorname{Rep}(\operatorname{Loc})(2)$ & Block(Rep) (9) & Loc*Trt (119) & MSE (467) & CV & $\mathrm{R} 2$ \\
\hline DTH & $6.17^{*}$ & $528.39^{* * *}$ & 2.03 & 3.13 & $6.71^{*}$ & 5.08 & 3.76 & 0.50 \\
\hline DTM & $91.66^{* * *}$ & 19.21 & 20.05 & 38.67 & 48.90 & 53.06 & 6.10 & 0.41 \\
\hline$A L$ & 2.35 & $744.61^{* * *}$ & 0.09 & 2.43 & $3.116^{* * *}$ & 2.08 & 9.90 & 0.59 \\
\hline$S L$ & 0.70 & $417.42^{* * *}$ & 0.15 & 0.81 & $0.937^{* * *}$ & 0.61 & 7.99 & 0.69 \\
\hline FLL & $9.99 *$ & 0.74 & 5.05 & $16.34^{*}$ & $11.21^{* *}$ & 7.81 & 8.48 & 0.43 \\
\hline$L N$ & 0.36 & 0.20 & $3.266^{* *}$ & $1.596^{* *}$ & 0.58 & 0.59 & 13.41 & 0.34 \\
\hline$L W$ & $1.01^{* * *}$ & 1.22 & 1.28 & 0.47 & $1.47^{* * *}$ & 0.61 & 8.54 & 0.51 \\
\hline SLA & $74296.73^{* *}$ & 744.4 & $212548.18^{*}$ & $128153.20^{* *}$ & $106403.69^{* * *}$ & 46296.14 & 17.03 & 0.52 \\
\hline $\mathrm{PH}$ & $25.00^{* *}$ & 4230.17 & $64.96^{*}$ & 4.76 & 19.61 & 16.21 & 4.05 & 0.56 \\
\hline$E F T$ & 0.82 & $972.99 * * *$ & 0.41 & 0.31 & 0.93 & 0.88 & 11.17 & 0.74 \\
\hline NGPP & $58.48^{* *}$ & $1565.57^{* * *}$ & 5.71 & 47.89 & $59.81^{* *}$ & 40.28 & 19.42 & 0.46 \\
\hline TSW & $28.25^{* * *}$ & 54.34 & 40.76 & 13.89 & $22.30^{*}$ & 16.84 & 10.53 & 0.45 \\
\hline SYPP & $13.40^{* * *}$ & $868.34^{* * *}$ & 5.88 & 11.81 & $11.77^{* *}$ & 7.80 & 26.35 & 0.52 \\
\hline SYPH & $0.54^{* * *}$ & $34.89^{* * *}$ & 0.21 & 0.45 & $0.47^{* *}$ & 0.31 & 26.38 & 0.52 \\
\hline
\end{tabular}

Description of the abbreviations under "Traits" column is given in Table 3

Bolded numbers in brackets (first row) represent the degrees of freedom (Df)

Trt treatments (collections), Loc location, Rep(Loc) replication within location, Block(Rep) block within replication, Loc*Trt location-treatment interaction, MSE mean square error, $C V$ coefficient of variation, $R^{2}$ coefficient of genetic determination

*significant at $p<0.05,{ }^{* *}$ highly significant at $p<0.01,{ }^{* * *}$ highly significant at $p<0.001$ 
$(\boldsymbol{L} \boldsymbol{A})$. Similarly, estimates of genotypic variance $\left(\boldsymbol{\delta}^{2}{ }_{\mathrm{g}}\right)$ and variance due to genotype environment interaction $\left(\boldsymbol{\delta}^{2}{ }_{\mathrm{gl}}\right)$ each showed wide variations. In this regard, $\boldsymbol{\delta}^{2}$ ganged from 0.01 in spike length $(S \boldsymbol{L})$, leaf area $(\boldsymbol{L} \boldsymbol{A})$ and seed yield per hectare $(\boldsymbol{S Y P H})$ to 6.74 in days to maturity $(\boldsymbol{D T M})$ and $\boldsymbol{\delta}^{\mathbf{2}}$ gl ranged from 0.00 in effective fertile tiller $(\boldsymbol{E F T})$ to 15018.40 in leaf area.

All the traits considered scored a low (less than 10\%) genotypic coefficient of variation (GCV). Similarly, all have scored a low phenotypic coefficient of variation (PCV) and genotype-by-environment coefficients of variation (GECV) except two, seed yield per plot (SYPP) and seed yield per hectare $(\boldsymbol{S Y P H})$ which had medium score. In general, estimates of PCV, GCV, and GECV showed a wide range of variations $(1.75 \%, 0.00 \%$ and $0.12 \%$ in days to heading $(\boldsymbol{D T H})$, leaf area $(\boldsymbol{L A})$, and days to maturity $(D T M)$ to $14.16 \%, 4.63 \%$, and $11.33 \%$ in seed yield per hectare $(\boldsymbol{S Y P H})$, in that order. The PCV estimates were higher than the corresponding GCV values for all the traits (Table 5).

With regard to estimates of heritability in broad sense $\left(\mathrm{H}^{2} \%\right)$, the traits considered showed large difference (from $0.00 \%$ or no heritability in leaf area $(\boldsymbol{L A})$ to $43.71 \%$ in days to maturity $(\boldsymbol{D T M}))$. However, the value (percent) heritable is low $(<40 \%)$ except in days to maturity which scored medium level (40-59\%) (Table 5). Similarly, estimates of genetic advance (GA) and genetic advance as a percent of traits mean (GA as \% mean) showed large variations (from 0.00 in leaf area in both to 3.53 in days to maturity and 3.40 in leaf number $(\boldsymbol{L N}))$ among the traits. However, the overall advance is very minimum with the maximum value not more than $4 \%$ (Table 5).

\section{Analysis of correlation coefficients}

Genotypic (above diagonal) and phenotypic (below diagonal) pairwise correlation coefficients for the traits considered are presented in Table 6. It was used to reveal the inter-relationship between the pairs of traits considered.

The genotypic variance of seed yield per plot and per hectare, one of the important traits in landrace food crops, showed a highly significant $(p<0.001)$ positive correlation with that of effective fertile tiller $(0.50)$, number of grains per plant $(0.80)$ and thousand seed weight $(0.53)$ and a significant $(p<0.05)$ positive correlation with days to heading (0.22) and stem length (0.20). Likewise, the phenotypic variance of these traits showed a highly significant positive correlation $(p<0.001)$ with five traits, such as days to heading (0.25), spike length (0.37), effective fertile tiller (0.52), number of grains per plant (0.67), and thousand seed weight (0.51) and a highly significant $(p<0.001)$ negative correlation with awn length $(-0.23)$. They also showed a significant $(p<0.05)$ positive correlation with leaf width $(0.10)$. In both the phenotypic and genotypic correlations, the magnitudes of three traits, such as number of grains per plant, thousand seed weight, and effective fertile tiller, in the order of magnitude, revealed a strong correlation $(\mathrm{r}>0.5)$ (Table 6).

Table 5 Estimates of trait mean, variance components, heritability, and genetic advance computed using pooled data of the 14 quantitative traits evaluated at the two test locations

\begin{tabular}{|c|c|c|c|c|c|c|c|c|c|c|}
\hline Traits & $\delta_{e}^{2}$ & $\delta_{g}^{2}$ & $\delta_{g l}^{2}$ & $\delta_{p}^{2}$ & GCV\% & PCV\% & GECV\% & $\mathrm{H}^{2} \%$ & GA & GAM \\
\hline DTH & 5.01 & 0.03 & 0.49 & 1.11 & 0.28 & 1.75 & 1.17 & 2.71 & 0.06 & 0.10 \\
\hline DTM & 52.02 & 6.74 & 0.02 & 15.42 & 2.18 & 3.29 & 0.12 & 43.71 & 3.53 & 2.96 \\
\hline$A L$ & 2.07 & 0.02 & 0.22 & 0.48 & 0.96 & 4.65 & 3.22 & 4.20 & 0.06 & 0.40 \\
\hline$S L$ & 0.61 & 0.01 & 0.07 & 0.14 & 1.03 & 3.70 & 2.67 & 6.95 & 0.05 & 0.53 \\
\hline FLL & 7.82 & 0.06 & 0.92 & 1.83 & 0.76 & 4.10 & 2.91 & 3.29 & 0.09 & 0.28 \\
\hline LN & 0.56 & 0.04 & 0.04 & 0.15 & 3.51 & 6.31 & 3.51 & 26.18 & 0.19 & 3.40 \\
\hline$L W$ & 0.61 & 0.05 & 0.21 & 0.26 & 2.40 & 5.00 & 4.97 & 19.58 & 0.18 & 2.01 \\
\hline$L A$ & 47058.6 & 0.01 & 15018.40 & 15352.31 & 0.00 & 9.81 & 9.70 & 0.00 & 0.00 & 0.00 \\
\hline$P H$ & 16.00 & 0.83 & 1.30 & 4.14 & 0.92 & 2.05 & 1.15 & 19.95 & 0.83 & 0.84 \\
\hline$E F T$ & 0.86 & 0.08 & 0.00 & 0.23 & 3.34 & 4.62 & 0.62 & 35.51 & 0.28 & 3.37 \\
\hline NGPP & 40.14 & 0.02 & 6.42 & 9.92 & 0.43 & 9.62 & 7.74 & 0.20 & 0.01 & 0.04 \\
\hline TSW & 16.77 & 0.95 & 1.93 & 4.71 & 2.49 & 5.57 & 3.57 & 20.17 & 0.90 & 2.31 \\
\hline SYPP & 7.80 & 0.24 & 1.36 & 2.21 & 4.62 & 14.03 & 11.04 & 10.65 & 0.33 & 3.07 \\
\hline SYPH & 0.31 & 0.01 & 0.05 & 0.09 & 4.63 & 14.16 & 11.33 & 10.83 & 0.07 & 3.15 \\
\hline
\end{tabular}

Description of the traits is given under Table 3

$\delta^{2}{ }_{e}$ environmental variance, $\delta^{2}{ }_{g}$ genotypic variance, $\delta^{2}{ }_{g l}$ variance due to genotype and location (environment) interaction, $\delta^{2}{ }_{p}$ phenotypic variance, $G C V(\%)$ genotypic coefficients of variation, $P C V(\%)$ phenotypic coefficients of variation, GECV (\%) genotype environment interaction coefficients of variation, $H^{2}$ (\%) heritability in broad sense, GA genetic advance, GAM genetic advance as percent of population mean 
Table 6 Genotypic (above diagonal) and phenotypic (below diagonal) correlation coefficients for Ethiopian barley landraces computed using data combined over the test locations

\begin{tabular}{|c|c|c|c|c|c|c|c|c|c|c|c|c|c|c|}
\hline Traits & DTH & DTM & $A L$ & $S L$ & $F L L$ & $L N$ & $L W$ & $S L A$ & $P H$ & $E F T$ & $N G P P$ & $T S W$ & SYPP & SYPH \\
\hline DTH & 1.00 & $0.28^{* *}$ & -0.08 & 0.15 & 0.12 & 0.11 & 0.10 & $0.29^{* *}$ & -0.09 & -0.01 & 0.15 & 0.13 & $0.22^{*}$ & $0.23^{*}$ \\
\hline DTM & $0.25^{* * *}$ & 1.00 & -0.05 & -0.12 & 0.15 & -0.09 & 0.08 & 0.17 & 0.06 & -0.01 & -0.08 & 0.03 & -0.05 & -0.05 \\
\hline$A L$ & $-0.23^{* * *}$ & 0.01 & 1.00 & $0.20^{*}$ & 0.02 & -0.07 & 0.15 & -0.07 & $0.18^{*}$ & 0.13 & -0.16 & 0.11 & -0.04 & -0.03 \\
\hline$S L$ & $0.30^{* * *}$ & $-0.08^{*}$ & $-0.25^{* * *}$ & 1.00 & -0.10 & 0.08 & 0.13 & -0.01 & $0.22^{*}$ & 0.11 & $0.197^{*}$ & 0.09 & $0.20^{*}$ & $0.20^{*}$ \\
\hline$F L L$ & $0.15^{* * *}$ & $0.20^{* * *}$ & -0.02 & 0.00 & 1.00 & -0.12 & 0.21 & $0.53^{* * *}$ & -0.11 & 0.07 & -0.06 & 0.06 & -0.01 & -0.01 \\
\hline$L N$ & $0.09^{*}$ & 0.02 & $-0.10^{* *}$ & $-0.09^{* *}$ & -0.03 & 1.00 & -0.08 & $0.39 * * *$ & -0.03 & 0.07 & -0.06 & $0.23^{*}$ & 0.08 & 0.07 \\
\hline$L W$ & $0.12^{* *}$ & $0.09^{*}$ & $0.10^{*}$ & $0.14^{* * *}$ & $0.31^{* * *}$ & 0.00 & 1.00 & $0.54^{* * *}$ & $0.21^{*}$ & 0.10 & 0.06 & 0.11 & 0.14 & 0.15 \\
\hline SLA & $0.21^{* * *}$ & $0.16^{* * *}$ & -0.05 & -0.01 & $0.59^{* * *}$ & $0.45^{* * *}$ & $0.53^{* * *}$ & 1.00 & 0.07 & 0.03 & -0.03 & $0.25^{* *}$ & 0.09 & 0.09 \\
\hline PH & $0.12^{* *}$ & 0.01 & $-0.12^{* * *}$ & $0.44^{* * *}$ & $-0.08^{*}$ & -0.02 & $0.18^{* * *}$ & 0.06 & 1.00 & -0.04 & -0.06 & $-0.20^{*}$ & -0.17 & -0.17 \\
\hline EFT & $0.32^{* * *}$ & -0.06 & $-0.39^{* * *}$ & $0.55^{* * *}$ & -0.02 & 0.03 & $0.10^{*}$ & 0.03 & $0.38^{* * *}$ & 1.00 & $0.19^{*}$ & $0.24^{* *}$ & $0.50^{* * *}$ & $0.50^{* * *}$ \\
\hline NGPP & 0.04 & -0.01 & 0.01 & 0.00 & 0.02 & 0.05 & 0.02 & -0.02 & $-0.15^{* * *}$ & $-0.11^{* *}$ & 1.00 & 0.04 & $0.80^{* * *}$ & $0.80^{* * *}$ \\
\hline TSW & 0.07 & 0.00 & 0.01 & $0.12^{* *}$ & 0.06 & 0.07 & 0.07 & $0.14^{* * *}$ & $-0.11^{* *}$ & $0.13^{* *}$ & $0.09^{* *}$ & 1.00 & $0.53^{* * *}$ & $0.53^{* * *}$ \\
\hline SYPP & $0.25^{* * *}$ & -0.03 & $-0.23^{* * *}$ & $0.37^{* * *}$ & 0.02 & 0.06 & $0.10^{*}$ & 0.05 & 0.07 & $0.52^{* * *}$ & $0.67^{* * *}$ & $0.51^{* * *}$ & 1.00 & $0.10^{* * *}$ \\
\hline SYPH & $0.25^{* * *}$ & -0.03 & $-0.22^{* * *}$ & $0.37^{* * *}$ & 0.01 & 0.05 & $0.08^{*}$ & 0.04 & 0.07 & $0.52^{* * *}$ & $0.67^{* * *}$ & $0.51^{* * *}$ & $0.10^{* * *}$ & 1.00 \\
\hline
\end{tabular}

Refer to Table 3 for the abbreviated codes of the traits

Bold values in the diagonal element indicate self-correlation

*Significant at $p<0.05,{ }^{* *}$ highly significant at $p<0.01,{ }^{* * *}$ highly significant at $p<0.001$

\section{Principal components and cluster analyses}

Both principal components analysis (PCA) and clustering were conducted using pooled standardized data of the 13 mathematically unrelated quantitative traits. Accordingly, the first six principal axes (eigenvalue $\geq 1.03$ ) in PCA accounted for $74.00 \%$ of the total variation (Table 7 ). The first principal component (PC1) accounted for $19.00 \%$ of the total variation. The variations in this plot were largely contributed by seed yield per plot (SYPP), thousand seed weight $(\boldsymbol{T S W})$, number of grains per plant (NGPP), and effective fertile tiller $(\boldsymbol{E F T})$ with contributing factor loadings of $0.55,0.38,0.37$, and 0.34 and 0.30 in that order. The second PC axis accounted for $15.00 \%$ of the total variation and differentiated the collections largely on the bases of single leaf area $(S L A ;-0.55)$, flag leaf length $(\boldsymbol{F L} \boldsymbol{L} ;-0.42)$, and leaf width $(\boldsymbol{L W} ;-0.38)$. The third and

Table 7 Eigenvalues and extent of variation for corresponding 13 components of mathematically unrelated quantitative characters in 120 Ethiopian barley landraces (see Table 3 for description of the variables)

\begin{tabular}{|c|c|c|c|c|c|c|}
\hline Variable & PC1 & PC2 & PC3 & PC4 & PC5 & PC6 \\
\hline DTH & 0.26 & -0.14 & -0.25 & 0.11 & 0.45 & 0.35 \\
\hline DTM & 0.05 & -0.28 & -0.23 & 0.29 & 0.24 & 0.53 \\
\hline$A L$ & 0.03 & -0.04 & 0.52 & -0.03 & -0.28 & 0.47 \\
\hline$S L$ & 0.21 & 0.11 & 0.45 & -0.04 & 0.34 & 0.09 \\
\hline$F L L$ & 0.14 & -0.42 & -0.13 & 0.24 & -0.35 & -0.13 \\
\hline$L N$ & 0.15 & -0.11 & -0.03 & -0.73 & 0.24 & -0.11 \\
\hline$L W$ & 0.24 & -0.38 & 0.29 & 0.23 & -0.06 & -0.24 \\
\hline$S L A$ & 0.30 & -0.55 & -0.04 & -0.15 & 0.05 & -0.27 \\
\hline $\mathrm{PH}$ & -0.06 & -0.14 & 0.52 & 0.11 & 0.36 & -0.09 \\
\hline$E F T$ & 0.34 & 0.12 & 0.16 & 0.00 & -0.37 & 0.11 \\
\hline NGPP & 0.37 & 0.36 & -0.06 & 0.32 & 0.19 & -0.31 \\
\hline TSW & 0.38 & 0.01 & -0.10 & -0.33 & -0.23 & 0.31 \\
\hline SYPP & 0.55 & 0.31 & -0.06 & 0.09 & -0.03 & -0.05 \\
\hline Eigenvalue & 2.52 & 1.99 & 1.54 & 1.30 & 1.20 & 1.03 \\
\hline Proportion & 0.19 & 0.15 & 0.12 & 0.10 & 0.09 & 0.08 \\
\hline Cumulative & 0.19 & 0.35 & 0.47 & 0.57 & 0.66 & 0.74 \\
\hline
\end{tabular}


Table 8 Pairwise generalized square distance $\left(D^{2}\right)$ between (below diagonal) and within (diagonal element) samples (collections) clusters and mean distance of each cluster from the other clusters (last column)

\begin{tabular}{lccccrc}
\hline Cls & $\mathbf{1}$ & $\mathbf{2}$ & $\mathbf{3}$ & $\mathbf{4}$ & $\mathbf{5}$ & Mean distance \\
\hline 1 & $\mathbf{1 . 1 4 ^ { * }}$ & & & & $\mathbf{1 0 . 2 9}$ \\
2 & $12.64^{* *}$ & $\mathbf{5 . 4 2 ^ { * }}$ & & $\mathbf{1 1 . 4 1}$ \\
3 & $8.63^{*}$ & $9.58^{*}$ & $\mathbf{2 . 6 4 ^ { * }}$ & $\mathbf{9 . 1 6}$ \\
4 & $8.75^{*}$ & $7.52^{*}$ & $7.70^{*}$ & $\mathbf{7 . 3 8 ^ { * * }}$ & $\mathbf{1 0 . 3 6}$ \\
5 & $11.12^{* *}$ & $15.90^{* *}$ & $10.73^{* *}$ & $17.49^{* *}$ & $\mathbf{5 . 1 8 ^ { * }}$ & $\mathbf{1 3 . 8 1}$ \\
\hline
\end{tabular}

Bolded and italicized values indicate within population pairwise square distance Cls clusters, Df4

*Significant at 0.05 probability, ${ }^{* *}$ significant at 0.01 probability level, ${ }^{* * *}$ significant at 0.001 probability level

fourth PCs axis contributed $12.00 \%$ and $10.00 \%$ of the total variations, respectively, with high contributing factor loadings from plant height $(\boldsymbol{P H} ; 0.52)$, awn length $(\boldsymbol{A} \boldsymbol{L} ; 0.52)$ and spike length $(\boldsymbol{S} \boldsymbol{L} ; 0.45)$ in the third $\mathrm{PC}$ axis and leaf number $(\boldsymbol{L N} ;-0.73)$ in the fourth PC axis. The fifth and sixth PCs axis each contributed less than $10.00 \%$ of the total variations and had high factor loadings from days to heading $(\boldsymbol{D T H} ; 0.45)$ and days to maturity $(\boldsymbol{D T M}$; 0.53), respectively (Table 7).

Similarly, PCA loading plot showed a very strong and close correlation among such traits as seed yield per plot $(\boldsymbol{S Y P P})$, number of grains per plant (NGPP), effective fertile tiller $(\boldsymbol{E F T})$, and thousand seed weight $(T S W)$. Moreover, there exists a strong positive correlation among the remaining traits except plant height (PH) (Fig. 2).

PCA score plot revealed that the entire samples were grouped roughly into four groups. However, the grouping pattern weakly followed proximity of the collection sites and/or other morphological similarities including seed colors. Thus, the result showed that several landraces from different administrative woredas that are even far apart were clustered together and landraces sampled from the same woreda were placed under different groups. Similarly, landraces having similar morphological features such as seed color and raw number were grouped under different clusters and vice versa (Fig. 3).

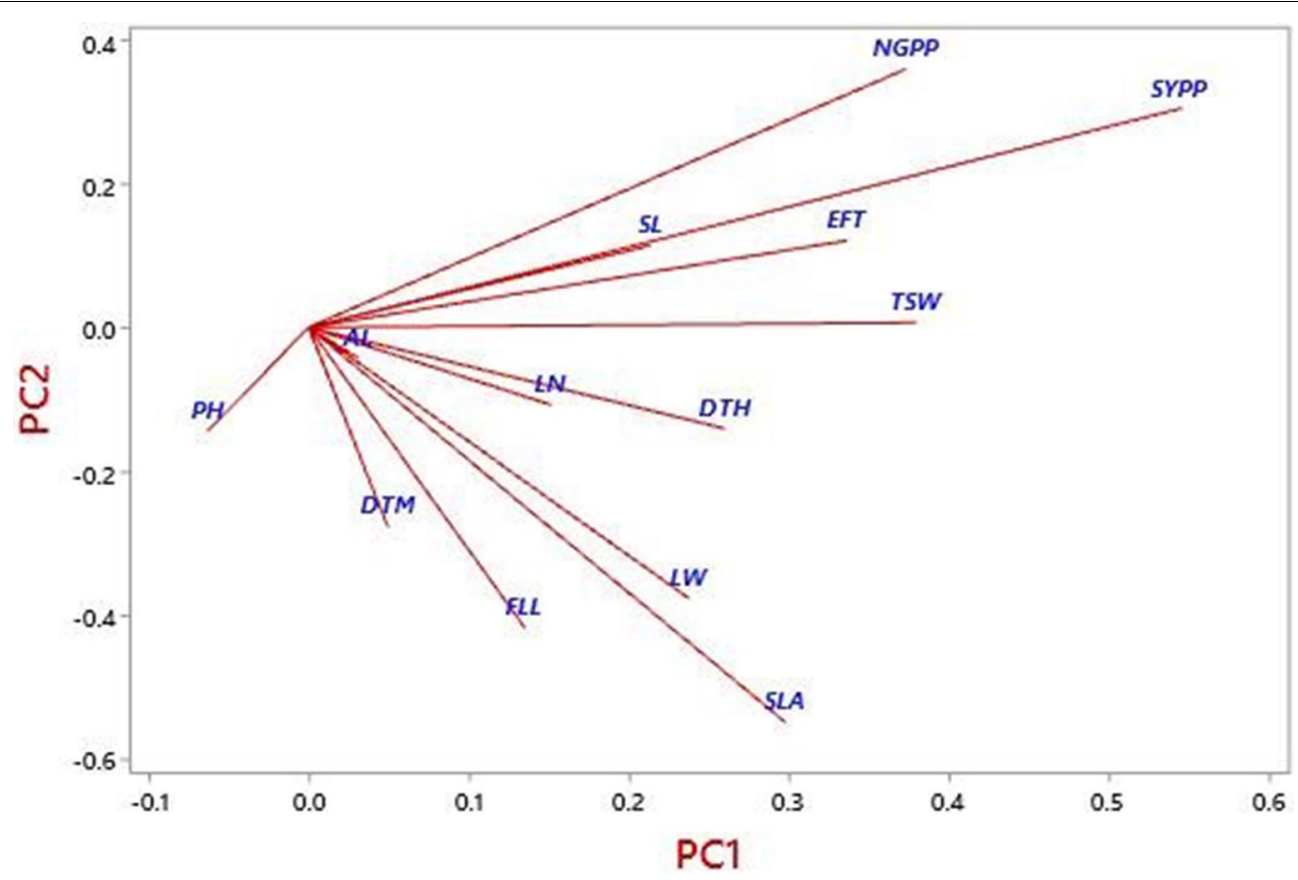

Fig. 2 Loading plot for the 13 quantitative traits; description of the abbreviated codes for the traits (variables) are indicated in Table 3 
Clustering of the entire 120 landraces revealed roughly five major clusters (Fig. 4), but with very loose association between and among the sites (geographic regions) of collections and thus, similar to PCA score plot, not in agreement with the concepts of isolation by distance. Landraces grouped under clusters two (C2) vs four (C4) (7.52), and three (C3) vs four (C4) (7.70) had nearly smaller cluster distance relative to samples grouped under clusters four (C4) vs five (C5) (17.49), and two (C2) $\boldsymbol{v} \boldsymbol{s}$ five (C5) (15.90). Samples grouped under clusters four and one had the largest (7.38) and smallest (1.14) inter cluster distances, respectively. The average distance of all the clusters is nearly similar with cluster five (C5) being most distant (13.81) from all the clusters (Table 8).

\section{Discussion}

\section{Patterns of variations and effects of selection pressure}

The present study revealed a wide range of variations in frequency distribution of the qualitative traits. There have been similar reports on barley accessions from Ethiopia [17, 26-29]. However, there is no pronounced variation across the collection sites and thus, dominance or rarity of the morphotypes is nearly uniform. Such stable distribution regardless of individual frequency differences in each character state could have resulted from similarity in use preference (utilization) among farmers

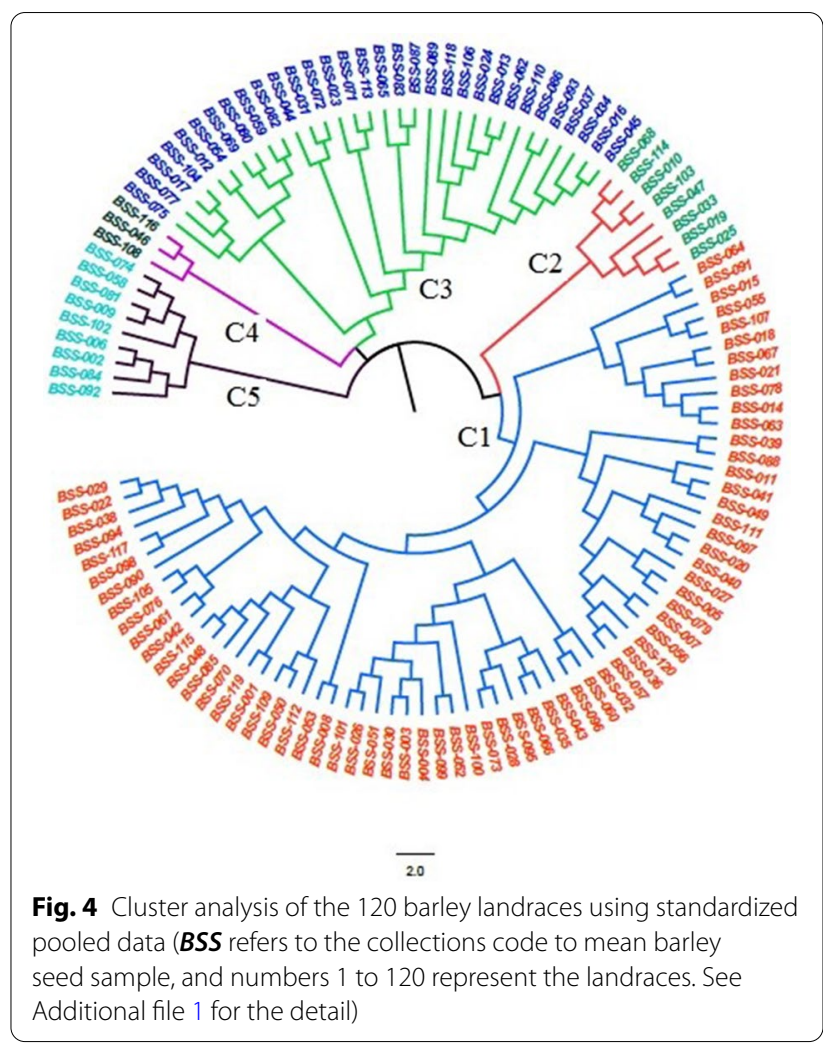

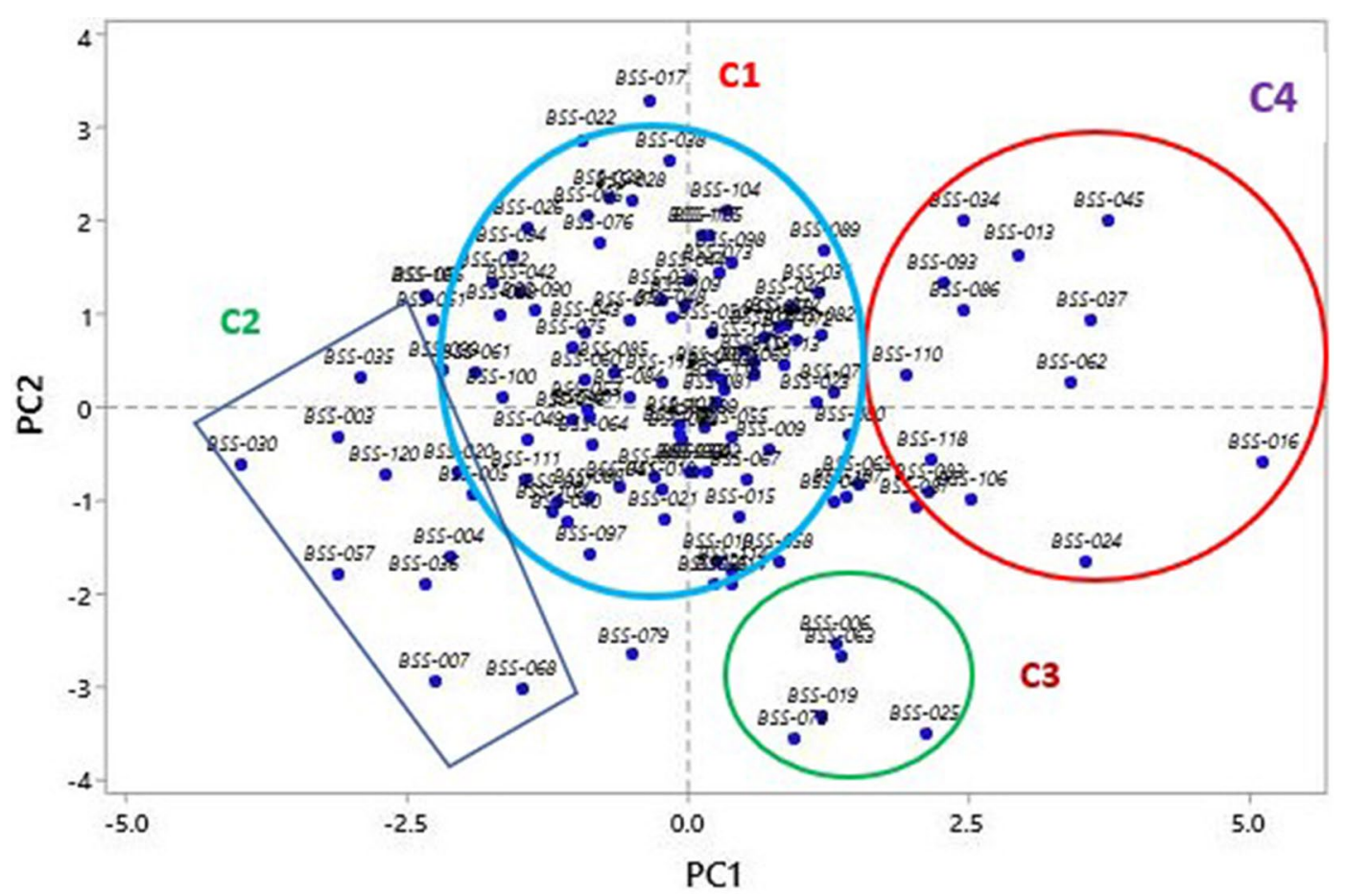

Fig. 3 Score plot for the 120 Ethiopian barley landraces considered in present study. Letters with numbers associated with blue dots indicate collection code and their description is given under Table 3 
in the area regardless of difference in their ethnic and cultural background and religious outlook. Accordingly, landraces having white awn and glume colours with no lemma teeth are more frequent because of their appealing colour and thus favoured for making local foods such as 'marka' (porridge), kinche, kita (mini bread), and rarely injera (leavened pan cake type). On the other hand, landraces with black awn colour and brown glume colour are relatively rare because of their so called non appealing colours in making such foods. Instead, they are largely used for making local drinks such as 'tella' (fermented local drink) that is not widely produced in the areas and 'keneto' (unfermented local drink). Such selection pressure has resulted in decreasing cultivation of the black, brown and purple seeded landraces to the extents of total loose from some sites. Otherwise, they are equally important in bearing adaptive advantages in selection breeding and in supporting food security of the local poor. Kernel row number is another important trait to the farmers in the study area. In this regard, six-rowed landraces are largely favoured with the intention of getting high yield from a given plot relative to two-rowed and irregular types.

In general, populations or materials with ample variations are considered to be fit for selection breeding and conservation actions. Thus, the patterns of qualitative variations in the landraces considered could lay the bases for further improvement programmes and conservation measures of the crop. In addition, it signals that Ethiopian barley landraces in general and landraces in Bale highlands in particular bear higher extents of morphological and genetic diversity which could be partly attributed to the country's high ecological heterogeneity and being the centre of origin and/or diversity for the crop. However, there is a biased selection pressure which is limited to farmer's traditional knowledge, and not research based and as a consequence adversely affecting some landraces (morphotypes) and causing loss of important well adapted traits that could overcome the current changing climate and soil conditions. Thus, important actions should be in place to save such exposed landraces.

\section{Patterns of variation in quantitative traits and effects of environmental factors}

The mean performance patterns in the quantitative traits considered followed a similar pattern with the qualitative traits. Accordingly, most of the traits revealed a wide range of variations. For example, single leaf area, days to maturity, number of grains per plant and thousand seed weight showed more folds between the maximum and minimum values. The result could signal the existence of variations among the tested landraces. Similar result has been reported by Jalata et al. [30].
Likewise, analysis of variance (ANOVA) in the quantitative traits revealed a significant $(p<0.05)$ to highly significant $(p<0.01$ or $p<0.001)$ variations among the collections both at individual test location and when the locations are combined. Similar result had been reported in Ethiopian barley landraces collected from different parts of the country [31-33]. Alemayehu and Parlevliet [27], Assefa [28], and Lakew et al. [29] had also reported a significant variation in many of the quantitative traits in Ethiopian barley. Such significant variation shows the existence of large variability among the tested collections in narrow sense and barley landraces in Bale zone and Ethiopia, in broad sense. The result could be helpful in further maintenance work and improvement programmes of the crop. Similarly, the considerably medium to high coefficient of genetic determination $\left(\mathrm{R}^{2}\right)$ detected in some of the traits suggest a favourable condition to identify superior genotypes with respect to the traits.

However, the observed variations were not purely genetic rather partly contributed by environmental factors as evidenced from the significant variations in location (l) and location-genotype (treatment) interaction $\left(\delta_{\text {gl }}^{2}\right)$ in most of the traits. Similarly, the greater variability due to genotype-environment interaction $\left(\delta_{\mathrm{gl}}^{2}\right)$ for example, in single leaf area and number of grains per plant and the grater PCV values over GCV values in all the traits once again suggest the high impact of environment factors on the detected variations. Therefore, while testing barley landraces at multiple sites and using phenotypic variations for breeding, caution should be taken especially while using those traits with significant location-treatment interactions.

Furthermore, the low ( $<10 \%)$ GCV and PCV values in all the traits considered except seed yield per plant and seed yield per hectare which had medium (between 10 and 20\%) PCV, following Deshmukh et al. [34] delineations, and the considerable differences between GCV and $\mathrm{PCV}$, the smallest being 1.11 in days to maturity (DTM) and the largest being 9.81 in single leaf area $(\boldsymbol{L A})$, reaffirms the higher impacts of environmental factors on the variations. As a consequence, multiple test locations and years are important with much care to reveal the actual extents of genetic variations and thus to reduce the impacts due to environmental errors (factors) for use in stable and successful breeding as well as conservation actions. Likewise, greater number of landraces should be tested while employing morphological traits-based genetic improvements and conservation actions. Moreover, up-to-date molecular approach is a marker of choice to fully offset the high impacts of environmental factors and to select the target landraces. There had been similar reports on the pronounced effects of environmental factors in Ethiopian barley landraces collected from several 
parts of the country and tested over multiple test locations and years [30].

\section{Patterns in the heritable portion of the variations}

The heritable portion of a given total variations is an essential component of agro-morphological traits-based genetic diversity. It is the proportion of phenotypic variance that is credited to genetic variance and could be useful to estimate the progress of a given selection process. The extents are categorized into very high $(\geq 80 \%)$, moderately high $(60-79 \%)$, medium $(40-59 \%)$, or low $(<40 \%)$ [35]. Accordingly, all the traits considered in the present study had low heritability in broad sense $\left(\mathrm{H}^{2}\right)$ except days to maturity (DTM) which had medium estimate, and eventually low GCV suggesting that selection based on these traits could be challenging due to high role of the environment factors to the genetic variations.

The expected genetic advance as a percentage of the landraces mean (GAM) indicates the progress that could be expected from selection of the top $5 \%$ of the populations. It could be low $(<10 \%)$, moderate $(10-20 \%)$, or high $(>20 \%)$ [36]. In this regard, all the traits showed a low estimate that once again suggest their relative less importance for selection because of the high environmental effects.

\section{Correlations between the traits and implications for selection}

Analysis of pairwise correlation coefficient is employed to determine the direction and extents of relationship between two traits. Association between traits could be resulted from linkage between genes or genes effect (genotypic), or a result of environmental effects (phenotypic), or both [37]. Both components are important in measuring the strength of association between traits and hence, selection targeting a given trait results in progress and/or retrogress based on whether the magnitude is positive or negative, respectively [38]. With this sense, most of the traits showed slight differences in the observed genotypic and phenotypic correlation coefficient values but yet the phenotypic correlation coefficient values are higher and significant as compared to their corresponding genotypic correlation coefficient values because of the detectable environment effect.

If environment factors are properly managed, the estimates of some important agronomic traits are useful for selection breeding. For example, seed yield (seed yield per plot; $\boldsymbol{S Y P P}$ and seed yield per hectare; $\boldsymbol{S Y P H}$ ) one of the important targets of selection breeding showed a positive and significant phenotypic and genotypic correlation with days to heading $(\boldsymbol{D T H})$, stem length $(\boldsymbol{S L})$, effective fertile tiller $(\boldsymbol{E} \boldsymbol{F T})$, number of grains per plant (NGPP), and thousand seed weight (TSW). The result suggests the rewarding nature of those traits in improving the yield of barley landraces.

\section{Patterns of association in the landraces}

The patterns of association among the tested landraces were evaluated using PCA and cluster analysis. PCA is used to group the materials into distinct clusters based on a predefined model and eventually identify the traits that contributed most to the observed variations within a group of test materials. Thus, it offers wide opportunity to select appropriate parental lines in a pool of test materials for breeding and hybridization. In this view, the first six $P C$ axes (Eigenvalues $\geq 1.03$ ) accounted a cumulative variance of $74.00 \%$.

In PCA, variables with coefficients, or elements of eigen vector of large absolute magnitude (close to unity) and with more factor loadings reflect a strong influence for a given trait and vice versa [39]. They also contribute more to the divergence of collections and are given greater emphasis to select the clusters for selection [40]. Thus, traits with high factor loadings, for example; leaf number $(\boldsymbol{L N})$, seed yield per plot (SYPP), single leaf area $(S L A)$, and thousand seed weight $(T S W)$ exhibited great influence on the phenotype of the landraces and could be targets of selection breeding.

Cluster analysis is another method to determine the pattern and extents of association between or among test materials. Accordingly, the entire collections formed five clusters (groups), with a very weak trend of geographic area of collections-based grouping pattern. Thus, the tendency of association between extents of genetic diversity and geographical proximity is very weak.

In general, the pattern of association exhibited in barley landraces is not in line with the notions of 'isolation by distance and origin' forwarded by Falconer [41]. The concept suggests that variation in origin (geographical separation or ancestral relationship), gene frequency and morphology is the probable sources of genetic diversity. The discordance of genetic diversity and geographical diversity (proximity) in the present study might be attributed to several interfering factors such as gene flow in the form of germplasm exchange, historical common origin of the collections, and may be due to smaller sample size or relatively narrow sampling area.

\section{Conclusions}

Ethiopian barley landraces are suffering from high genetic erosion and their current production is largely limited to marginal and degraded plots of land that are not meant for production of other crops. Such marginalized production is largely because of its local endemicity and lack of research attention and thus, its restricted market demand unlike other crops in the country such as 
wheat and teff. Hence, the extents of its genetic variability reported in the present study could be used as baseline to offer breeders and conservationists a timely and good opportunity for successful selection and management. However, regardless of the observed considerable range of variations and reasonable diversity among the entire landrace samples, it may be of importance to further reveal the genetic-based variability through intensive collection from all growing areas of the country and testing at multiple sites and over multiple years so that its genetic improvement and potential sites for conservation and development of best-performing lines could be explicit. Likewise, collaborative efforts of all stakeholders are equally important to taking appropriate ex situ and in situ conservation actions and creating awareness among farmers in order not to overlook the landraces in terms of both production and productivity.

\section{Abbreviations}

ANOVA: Analysis of variance; DD: Decimal degree; Masl: Meter above sea level; NMSA: National Meteorology Service Authority; PCA: Principal Components Analysis.

\section{Supplementary Information}

The online version contains supplementary material available at https://doi. org/10.1186/s40066-021-00335-4.

Additional file 1: List of standard qualitative and quantitative agromorphological traits used in the present study along with their codes and descriptions (superscripts, a stand for qualitative traits and b for quantitative traits)

Additional file 2: The 120 barley landrace samples used in the present study along with their assigned code, collections administrative woredas, kebeles, altitude (m.a.s.l), latitude (DD) and longitude (DD).

Additional file 3: Mean separation among the 120 barley landrace samples used in the present study in each of the 14 quantitative traits used computed using LSD at 5\% significance level; see Table 3 for description of the traits

\section{Acknowledgements}

The authors would like to acknowledge Madda Walabu University, research and community engagement office and the University's postgraduate programme for financial, material and technical supports to this research. The authors would like to extend their heartfelt thanks to volunteer farmers in all the study kebeles for their unreserved assistance in providing us landrace samples and all other valuable information.

\section{Authors' contributions}

FG carried out sample collection, field design, and data analysis. MA conducted experimental design and data analysis. TB carried out sample collection, field experiment, and data collection and analysis. FG, MA and TB participated in experimental design, data interpretation and drafting the manuscript. All authors have read and approved the final manuscript.

\section{Funding}

The research was supported by Madda Walabu research and community service engagement office through the universities postgraduate programme.

\section{Availability of data and materials}

List of standard qualitative and quantitative agro-morphological traits used in the present study along with their codes and descriptions study (superscripts, ${ }^{a}$ stand for qualitative traits and ${ }^{b}$ for quantitative traits) is provided in Additional file 1. Full passport data of the 120 landrace samples used in the present study along with their assigned code, collections administrative woredas, kebeles, altitude (m.a.s.l), latitude (DD) and longitude (DD) is provided in Additional File 2. Mean separation among the 120 barley landrace samples used in the present study in each of the 14 quantitative traits used computed using LSD at 5\% significance level; see Table 3 for description of the traits, is provided in Additional File 3.

\section{Declarations}

Ethics approval and consent to participate

Not applicable.

\section{Consent for publication}

Not applicable.

\section{Competing interests}

The authors declare that they have no competing interests.

\section{Author details}

${ }^{1}$ Department of Biology, Madda Walabu University, P.O. Box 247, Bale Robe, Ethiopia. ${ }^{2}$ Department of Statistics, Madda Walabu University, P.O. Box 247, Bale Robe, Ethiopia.

Received: 3 June 2020 Accepted: 16 August 2021

Published online: 20 December 2021

\section{References}

1. Lev-Yadun S, Gopher A, Abbo S. The cradle of agriculture. Science. 2000;288:1602-3. https://doi.org/10.1126/science.288.5471.1602.

2. Akar T, Avci M, Dusunceli F. Barley: Post harvest operations. Food and Agriculture Organization (FAO) of the United Nations, The Central Research Institute for Field Crops, Ankara, Turkey; 2004. p. 64.

3. Vavilov NI. The origin, variation, immunity and breeding of cultivated plants. Chro Bot. 1951;13:1-366.

4. Negassa M. Geographic distribution and genotypic diversity of resistance to powdery mildew of barley in Ethiopia. Hereditas. 1985;102:113-21.

5. Bekele E. Differential rate of regional distribution of barley flavonoid patterns in Ethiopia, and a view on the centre of origin of barley. Hereditas. 1983:98:269-80.

6. FAO/WFP. Ethiopia-FAO/WFP Crop and Food Security Assessment Mission. Special Report Food and Agriculture Organization: Rome; 2012.

7. Teshome A, Brown AHD, Hodgkin T. Diversity in landraces of cereal and legume crops. Plant Breed Rev. 2001;21:221-61.

8. Lakew B, Semeane Y, Alemayehu F, Hailu G, Grando S, Van Leur JAG, Ceccarelli S. Exploiting and diversity of barley landraces in Ethiopia. Genet Resour Crop Evol. 1997:44:109-16.

9. Alemayehu F, Lakew B, Bekele B. On-farm evaluation of promising food barley cultivars in North and NW Shewa zones. Workshop, Holeta Agricultural Research Centre, Holeta, Ethiopia. 16-18; 2001.p. 200-11.

10. Asfaw Z. Variation in the morphology of the spike within Ethiopian barley (Hordeum vulgare L.) (Poaceae). Acta Agric Scand. 1988;38:277-88.

11. Teshome A, Baum BR, Fahrig L, Torrance JK, Arnason JT, Lambert JD. Sorghum (Sorghum bicolor (L.) Moench) landrace variation and classification in North Shewa and South Welo, Ethiopia. Euphytica. 1997;97:255-63.

12. Shewayrga $H$, Sopade PA. Ethnobotany, diverse food uses, claimed health benefits and implications on conservation of barley landraces in North Eastern Ethiopia highlands. J Ethnobiol Ethnomed. 2011;7(19):1-15.

13. Worede M, Tanto T, Feyissa R. Keeping diversity alive: an Ethiopian perspective. In: Brush SB, editor. Genes in the field, on-farm conservation crop diversity. Boca Raton: Lewis Publishers; 2000. p. 143-61.

14. Ryding O, Iwasson M, Morton JK, Persson E, Sebald O, Seybold S, Lamiaceae DS. Flora of Ethiopia and Eritrea. Sweden: The national herbarium, 
Addis Ababa University, Ethiopia and Department of Systematic Botany, Uppsala University; 2006. p. 592-5.

15. National meteorological service authority (NMSA). Ethiopia: Bale zone branch; 2010.

16. IPGRI. Descriptors for barley. Rome: International Plant Genetic Resources Institute; 1994.

17. Tanto H, Rau D, Bitocchi B, Papa P. Genetic diversity of barley (Hordeum vulgare L.) Landraces from the central highlands of Ethiopia: comparison between the Belg and Meher growing seasons using morphological traits. Genet Resour Crop Evol. 2009;56:1131-48.

18. Negassa M. Patterns of phenotypic diversity in an Ethiopian barley collection, and the Arsi-Bale Highland as a centre of origin of barley. Hereditas. 1985;102:139-50.

19. Minitab LLC. Minitab Statistical Package for Windows. State college: Minitab Inc; 2019.

20. Gomez KA, Gomez A. Statistical procedures for agricultural research. 2nd ed. New York: Wiley; 1984. p. 680.

21. Singh RK, Chaudhary BD. Biometrical methods in quantitative genetic analysis. New Delhi: Kalyani Publishers; 1985. p. 13-55.

22. Allard RW. Principle of plant breeding. New York: Wiley; 1960.

23. Sharma JR. Statistical and biometrical techniques in plant breeding. Calcutta: New Age International Limited Publishers; 1998.

24. Robertson GR. The sampling variances of the genetic correlation coefficients. Biometrics. 1959;15:469-85.

25. Andrew R. FigTree: Tree figure drawing tool Version 1.4.3. Institute of Evolutionary Biology, United Kingdom, University of Edinburgh. 2016. http:// tree.bio.ed.ac.uk/software/figtree/. Accessed Mar 2020.

26. Kebebew F, Tsehay Y, McNeilly T. Morphological and farmers cognitive diversity of barley (Hordeum vulgare L. (Poaceae)) at Bale and North Shewa of Ethiopia. Genet Resour Crop Evol. 2001;48:67-481.

27. Alemayehu F, Parlevliet JE. Variation between and within Ethiopian barley landraces. Euphytica. 1997;94:183-9.

28. Assefa A, Labuschagne MT. Phenotypic variation in barley (Hordeum vulgare L.) landraces from north Shewa in Ethiopia. Biodiv Conserv. 2004;13:1441-51.

29. Lakew L, Semeane Y, Alemayehu F, et al. Exploiting the diversity of barley landraces in Ethiopia. Genet Resour Crop Evol. 1997;44:109-16.

30. Jalata Z, Ayana A, Zeleke H. Variability, heritability and genetic advance for some yield and yield related traits in Ethiopian barley (Hordeum vulgare L.) landraces and crosses. Int J Plant Breed Genet. 2011;5:44-52.
31. Negassa M. Patterns of phenotypic diversity in an Ethiopian barley collection and the Arussi-Bale highland as a center of origin of barley. Hereditas. 1985;102:139-50.

32. Demissie A, Bjørnstad A. Geographical, altitude and agro-ecological differentiation of isozyme and hordein genotypes of landrace barleys from Ethiopia: implications to germplasm conservation. Genet Resour Crop Evol. 1997:44:43-55.

33. Abebe TD, Bauer AM, Léon J. Morphological diversity of Ethiopian barleys (Hordeum vulgare L.) in relation to geographic regions and altitudes. Hereditas. 2010;147:154-64.

34. Deshmukh SN, Basu MS, Reddy PS. Genetic variability, character association and path coefficient analysis of quantitative traits in Virginia bunch varieties of groundnut. Indian J Agric Sci. 1986;56:816-21.

35. Singh BD. Plant breeding: principles and methods. New Delhi: Kalyani Publishers; 2001. p. 896.

36. Johnson HW, Robinson HW, Comstock R. Estimates of genetic and environmental variability in soybeans. Agron J. 1955;47:314-8.

37. Shafique MS, Ahsan M, Mehmood Z, Abdullah M, Shakoor A, Ahmad MI. Genetic variability and interrelationship of various agronomic traits using correlation and path analysis in Chickpea (Cicer arietinum L.). Acad J Agric Res. 2016;4(2):082-5.

38. Akinwale MG, Gregorio G, Nwilene F, Akinyele BO, Ogunbayo SA, Odiyi AC. Heritability and correlation coefficient analysis for yield and its components in rice (Oryza sativa L.). Afr J Plant Sci. 2011;5:207-12.

39. De Lacy $H$, Cooper M. Pattern analysis for the analysis of regional variety trials. In: Kang MS, editor. Genotype-by-environment interaction and plant breeding. Baton Rouge: Louisiana State University; 1990. p. 301-34.

40. Jagadev PN, Samal KM, Lenka L. Genetic divergence in rape mustard. Indian J Genet. 1991;51:465-6.

41. Falconer DS. Introduction to quantitative genetics. 2nd ed. London: Longmans Green; 1981.

\section{Publisher's Note}

Springer Nature remains neutral with regard to jurisdictional claims in published maps and institutional affiliations.

Ready to submit your research? Choose BMC and benefit from

- fast, convenient online submission

- thorough peer review by experienced researchers in your field

- rapid publication on acceptance

- support for research data, including large and complex data types

- gold Open Access which fosters wider collaboration and increased citations

- maximum visibility for your research: over $100 \mathrm{M}$ website views per year

At BMC, research is always in progress.

Learn more biomedcentral.com/submissions 